\title{
Diagnostic utility of bone marrow aspiration biopsy in definitive diagnosis in cases of hepatosplenomegaly.
}

1. MBBS, M.Phil (Histopathology) Demonstrator Pathology Federal Medical \& Dental College, Islamabad.

2. MBBS, M.Phil (Hematology) Assistant Professor Hematology Khyber Medical College, Peshawar.

3. BDS, MSPH

Demonstrator Community Medicine Bolan Medical College, Quetta.

Correspondence Address:

Dr. Muhammad Ihtesham Khan

Department of Pathology

Khyber Medical College.

ihteshamkhan9@yahoo.com

Article received on:

09/07/2019

Accepted for publication:

10/10/2019

\begin{abstract}
Asmara Sami ${ }^{1}$, Muhammad Ihtesham Khan ${ }^{2}$, Sami Iqbal ${ }^{3}$
ABSTRACT... Objective: To determine the diagnostic utility of bone marrow aspirate in finding cause of hepatosplenomegaly. Study Design: Cross Sectional Descriptive study. Setting: Pathology Department of Khyber Teaching Hospital. Period: August 2017 to December 2017. Material \& Methods: A total of 116 cases were referred to Pathology department for workup of hepatosplenomegaly during study period. Patients were subjected to bone marrow aspiration and biopsy. The cases were diagnosis was made and those where no specific diagnosis could be made were noted. Mean and standard deviation were used for quantitative variables. Frequency and percentages were used for qualitative variables. Results: Mean age of the study sample was $45 \pm 9$ years (range 2 - 64 years). There were $66(56.89 \%)$ males and $50(43.10 \%)$ females. No specific diagnosis could be made in $36(31.03 \%)$ cases of hepatosplenomegaly. In remaining $80(68.96 \%)$ cases a definitive diagnosis could be made on examining bone marrow aspiration. So the diagnostic utility of bone marrow aspiration examination was $68.96 \%$. Conclusion: Bone marrow aspiration is valuable and diagnostically important tool for workup of cases of hepatosplenomegaly.
\end{abstract}

Key words: $\quad$ Bone Marrow Aspiration, Hepatosplenomegaly.

Article Citation: Sami A, Khan MI, lqbal S. Diagnostic utility of bone marrow aspiration biopsy in definitive diagnosis in cases of hepatosplenomegaly. Professional Med $\mathrm{J}$ 2021; 28(2):214-217. https://doi.org/10.29309/TPMJ/2021.28.02.3928

\section{INTRODUCTION}

Bone marrow aspiration is an important tool to make final diagnosis in cases of hepatosplenomegaly. ${ }^{1-6}$ Sometimes, the cause of hepatosplenomegaly may not be easily found by history and clinical examination of the patient. ${ }^{7}$ So, it may become difficult to reach the final diagnosis. ${ }^{2,7}$ In such cases, the physician advises the patient to undergo bone marrow aspiration, in order to reach the final diagnosis. ${ }^{7,8}$ In majority of the cases of hepatosplenomegaly, the bone marrow examination gives the final diagnosis. But in some cases, the findings of bone marrow aspiration are nonspecific and thus no definitive diagnosis can be made. These are the cases where fine needle aspiration cytology or biopsy of liver and spleen is advised to make final diagnosis.

Abnormal increase in the size of liver and spleen is called hepatosplenomegaly. ${ }^{9}$ Usually, the spleen is said to have increased in size when it moves below left costal margin. ${ }^{10}$ The liver is said to have increased in size when its lower margin goes below the right costal margin. ${ }^{10}$ The ultrasound scan shows enlargement of liver and spleen, no matter how minute the enlargement may be. ${ }^{10}$ Ultrasound scan can also detect the hepatosplenomegaly that has been missed by clinician on clinical examination of the abdomen, So, ultrasound scan is almost always advised to look for the presence or absence of hepatosplenomegaly.

Very scanty data is available regarding diagnostic significance of bone marrow biopsy in cases of hepatosplenomegaly. Therefore, the present study was done with a rationale to determine the diagnostic significance of bone marrow aspirate in reaching to final diagnosis in cases presenting with hepatosplenomegaly.

\section{MATERIAL \& METHODS}

This cross sectional descriptive study was 
conducted in Pathology Department, Khyber Teaching Hospital. The study was from August 2017 to December 2017 i.e 5 months duration. The ethical committee approved the research with letter no. 16/ADR/KMC. Patients of all ages and both the sexes referred to hematology department for workup of hepatosplenomegaly were included in the study. A total of 116 cases were included in the study. Sampling was done through Non probability purposive sampling technique. Bone marrow aspiration was performed under local anesthesia. The slides were examined by a consultant hematologist and opinion was taken from histopahtologist with regards to morphology. The cases where diagnosis could be made on basis of bone marrow aspirate were noted down. The diagnostic utility of bone marrow aspirate was calculated accordingly. Quantitative variables were analyzed by mean and standard deviation. Quantitative variables were measured by frequency and percentages.

\section{RESULTS}

Age and gender distribution of 116 cases of hepatosplenomegaly are given in table 1 and Figure-1 respectively. Diagnostic utility of bone marrow biopsy in diagnosing cases of hepatosplenomegaly is shown in Table-Il.

\begin{tabular}{|l|c|c|}
\hline \multicolumn{1}{|l|}{ Age } & Range & Mean \pm SD \\
\hline $2-64$ years & $45 \pm 9$ years \\
\hline
\end{tabular}

Table-I. Age distribution of the study sample $(n=116)$.

\section{DISCUSSION}

Usually, clinical examination of the abdomen and ultrasonography of the abdomen are sufficient to confirm the presence or absence of hepatosplenomealy in patients. ${ }^{1,11}$ But to find its cause, it is necessary to properly investigate it.

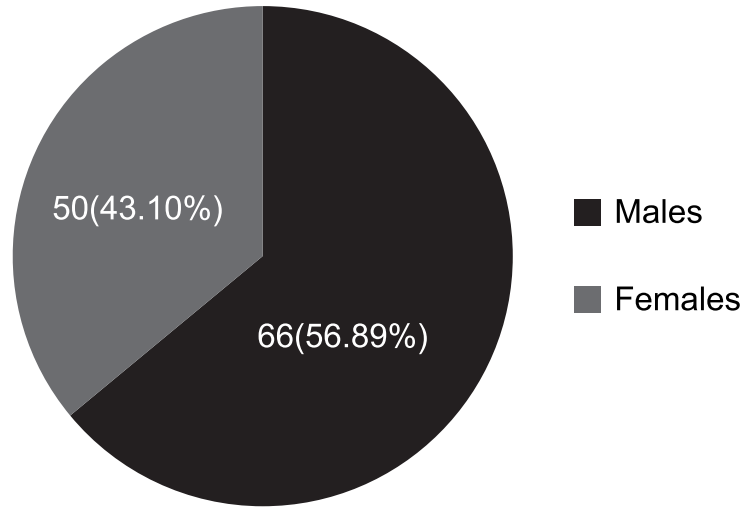

Figure-1. Gender distribution in study population $(n=116)$.

It is also necessary because it may be due to some serious pathology like leukemia .Delayed diagnosis may cause delayed treatment and therefore a poor prognosis. ${ }^{12}$

Bone marrow aspirate and biopsy is considered a very important investigative tool to confirm or exclude the final diagnosis in cases with hepatosplenomegaly. In certain cases, the diagnosis can be made by examining bone marrow aspiration smears. But in certain cases, no definitive diagnosis can be made by bone marrow examination. In such cases, patients are advised to do lymph node biopsy to find the cause.

In our study, the mean age of the study population was $45 \pm 9$ years (range $=2-64$ years). There was male predominance in the study population. Similar data is reported by study of Jiskani SA. ${ }^{11}$

In our study diagnosis could be made in $68.96 \%$ cases. Thus, bone marrow aspiration biopsy was able to make final diagnosis in majority of the cases in our study. In the remaining 31.04\% cases, no specific diagnosis could be made.

\footnotetext{
Cases where final diagnosis could be made with bone marrow aspirate examination N (\%) $80(68.96 \%)$
}

Cases where final diagnosis could not be made with bone marrow aspirate examination N (\%)
Diagnostic utility of bone marrow aspiration in making final diagnosis in cases of hepatosplenomegaly (\%)

36 (31.04\%)

68.96

Table-II. Diagnostic utility of bone marrow aspiration biopsy in cases presenting with hepatosplenomegaly $(\mathrm{n}=116)$ 
These cases were either reactive or normocellular .Cases where bone marrow aspiration does not give any leads to diagnosis are advised to do fine needle aspiration cytology or biopsy of liver and spleen. In a study done by Jiskani SA, the bone marrow aspiration biopsy could make diagnosis in $68 \%$ cases, but could not make final diagnosis in $32 \%$ cases. ${ }^{11}$ These figures are somewhat close to that reported in our study. In another study done in Ghana, bone marrow aspiration biopsy could not make definitive diagnosis in about $23 \%$ cases, while in the remaining $77 \%$ cases, final diagnosis was made successfully. ${ }^{13}$ Thus, the diagnostic utility of bone marrow in making final diagnosis of hepatosplenomegaly is significantly high, and it should be always included in panel of investigation's for the workup of hepatosplenomegaly.

\section{Limitation of Study}

The study was done in a single tertiary care centre. There is a need to do bigger studies in this regard involving multiple tertiary care centres so that the results may be truly representative of whole population.

\section{CONCLUSION}

Bone marrow aspiration plays significant role in finding underlying diagnosis in cases of hepatosplenomegaly. Therefore, it should be always kept in investigation panel for the workup of hepatosplenomegaly in clinical setup

\section{Acknowledgement}

All glories be to Allah for helping me complete this research.

\section{Copyright@ 10 Oct, 2019.}

\section{REFERENCES}

1. Khan MI, Ahmad N, Fatima SH. Haematological disorders; analysis of hematological disorders through bone marrow biopsy examination. Professional Med J 2018; 25(6):828-34. DOI: 10.29309/ TPMJ/18.4500

2. Munir AH, Qayyum S, Gul A, Ashraf Z. Bone marrow aspiration findings in a tertiary care hospital of Peshawar. J Postgrad Med Inst 2015; 29(4): 297-300.
3. Addo GB, Amoako YA, Bates I. The role of bone marrow aspirate and trephine samples in haematological diagnoses in patients referred to a teaching hospital in Ghana. Ghana Med J. 2013; 47(2):74-8.

4. Padasaini S, Parsad KBR, Rauniyar SK, Shrestha R, Gautam K, Pathak R, et al. Interpretation of bone marrow aspiration in hematological disorders. $J$ Pathol Nepal 2012; 2: 309-12.

5. Syed NN, Moiz B, Adil SN, khurshid M. Diagnostic importance of bone marrow examination in nonhematological disorders. J Pak Med Assoc 2007; 57:123-5.

6. Stiffer S, Babarovic E, Valkovic T, Seili-Bekafigo I, Stemberger C, Nacinovic A, et al. Combined evaluation of bone marrow aspirate and biopsy is superior in the prognosis of multiple myeloma. Diagn Pathol 2010; 5:30: 1-7.

7. Khan A, AqeelM, Khan TA, Munir A. Pattern of hematological diseases in hospitalized paediatric patients based on bone marrow examination. JPMI. 2008. 22(3); 196-200.

8. Bain BJ. Bone marrow aspiration. J ClinPathol 2001; 54:657-63.

9. Champatiray J, Panigrahi D, Mondal D, Satpathy SK. Study of aetiological profile, clinical presentation and outcome of hepatosplenomegaly in children between 1 month and 14 years of age. Int J Contemp Pediatr. 2017; 4(3):927-32.

10. Anusha G, Somaiah G, Siddique AM, Srikanth B, Babu M S, Vamsidhar NS. Study of Etiological and Clinical Profile of Hepatosplenomegaly in Children between 1 Month and 15 Years of Age. Sch J App Med Sci. $2014 ; 2(2): 554-7$

11. Jiskani SA, Sohail A, Naseem L, Zawar A, Rizwan $\mathrm{H}$, Ali $\mathrm{S}$, et al. Clinico-hematological profile of hepatosplenomegaly in pediatric population based on bone marrow biopsy. Pak J Pathol. 2018: 29(2): 37-9

12. Humaira M, Ahmed A, Memon A, Siddique SA, Hayee PA, Ghani $\mathrm{MH}$ et al. Etiological Pattern of Splenomegaly in Adults at Tertiary Care Hospital Jamshoro Sindh. J Liaquat Uni Med Health Sci. 2016; 15(01):40-5.

13. Addo GB, Bates I. Causes of massive tropical splenomegaly in Ghana. Lancet. 2002; 360 (9331): 449-54. 


\begin{tabular}{|c|l|l|}
\hline \multicolumn{3}{|c|}{ AUTHORSHIP AND CONTRIBUTION DECLARATION } \\
\hline Sr. \# & Author(s) Full Name & \multicolumn{1}{|c|}{ Contribution to the paper } \\
\hline 1 & Asmara Sami & Principle author. \\
\hline 2 & M. Ihtesham Khan & $\begin{array}{l}\text { Data compilation and analysis, } \\
\text { Result compilation, Main idea. } \\
\text { Literature review, Discussion } \\
\text { Critical review. }\end{array}$ \\
\hline 3 & Sami lqbal & \\
\hline
\end{tabular}

